\title{
Neuroendocrine and Psychological Assessment in a Guinness 10 Days Scuba Dive
}

\author{
Authors \\ L. Revelli ${ }^{1}$, G. Addolorato ${ }^{2}$, A. D’Amore ${ }^{1}$, C. Carrozza ${ }^{3}$, G. Giubileo ${ }^{4}$, A. Puiu ${ }^{4}$, C. P. Lombardi ${ }^{1}$, R. Bellantone ${ }^{1}$, \\ G. Gasbarrini ${ }^{2}$, Progetto Abissi 2005 Dive Medical Group ${ }^{2}$ \\ Affiliations \\ ${ }^{1}$ Department of Endocrine Surgery, Catholic University of Rome, Rome, Italy \\ 2 Department of Internal Medicine, Catholic University of Rome, Rome, Italy \\ ${ }^{3}$ Department of Biochemistry and Clinical Biochemistry, Catholic University of Rome, Rome, Italy \\ ${ }^{4}$ Research Centre, ENEA Frascati, Frascati, Italy
}

\author{
Key words \\ - stress \\ - scuba divers \\ - anxiety \\ - depression \\ - cortisol
}

accepted after revision August 14, 2006

\section{Bibliography}

DOI 10.1055/s-2007-964910 Int J Sports Med 2007; 28: 1 - 5 (c) Georg Thieme Verlag KG Stuttgart $\cdot$ New York . ISSN 0172-4622

\section{Correspondence}

Prof. Giovanni Addolorato Department of Internal

Medicine

Catholic University of Rome

Largo A. Gemelli 8

00168 Rome

Italy

Phone: + 390630154334

Fax: + 390635502775

g.addolorato@rm.unicatt.it

\section{Abstract \\ $\nabla$}

This study was designed to evaluate physiological and psychological stress parameters in 2 professional trained scuba divers, using a unique physiopathologic model, offered by the guinness 240 hours scuba dive. Two scuba dive masters have spent 240 hours at 6-8 meters depth (26.4 ft) in Ponza Island water (Italy). Blood samples were collected daily in the underwater bell; samples were carried out of water in waterproof bags. Breath samples were collected, measuring ethylene release. Psychological assessment was performed using the State and Trait Anxiety Inventory and the Zung self-rating depression scale. In the studied subjects, cortisol and prolac-

\section{Introduction \\ $\nabla$}

Recreational scuba diving exposes individuals to environmental stresses not often encountered in other types of activity. These stresses include increased ambient pressure, raised partial pressure of oxygen, increased resistance to movement, added weight and drag of diving equipment, cold stress and a higher breathing resistance [6].

Several factors responsible for the injuries and fatalities occurring during this activity are described; among them, anxiety and panic are reported to be the main causes [13]. In this connection the ability to control anxiety in untrained scuba divers as well as the ability to manage stressful situations in experienced divers are demonstrated to be the best solution to prevent accidents [15].

At present, there are few data on the effect of long-term diving on stress parameters in professional scuba divers. The aim of the present study was to evaluate both physiological and psychological stress parameters in 2 professionally trained scuba divers, using a unique physiopa- tin showed physiological pulsatile secretion. Breath ethylene didn't exceed normal values. At the start of the study, no subjects showed high levels of state anxiety, trait anxiety and current depression. Psychometric scales scores remained steady during the diving period and no subjects showed anxiety and/or depression and/or panic symptoms during the time of observation. The present study shows that, although the long-time diving, well trained professional divers did not develop anxiety and/or depression. No subject discontinued the diving due to occurred psychological disorders or systemic events. The present report shows that the long-term diving permanence is possible, at least in well trained scuba divers.

thologic model offered by the guinness 240 hours scuba dive.

The 240-hour dive duration is being claimed as a record, breaking a previous 107 hours spent under water by a U.S. diver in Lake Michigan and doubling the 120 hours set by Jerry Hall of Bluff City, TN, USA, in eastern Tennessee's Watauga Lake, according to the Guinness world records (www.fishspringsmarina.com).

\section{Material and Methods \\ $\nabla$}

In September 2005, 2 scuba dive masters spent 240 hours (10 days) at a depth of $6-8$ metres $(26.4 \mathrm{ft})$ in the waters of Cala Feola, north west of Italy's Ponza Island (4053, 84 N 1257, 80 E), in the central Tirrenian (Mediterranean) sea as part of a scientific experiment into the effects of sustained immersion on the human body.

Diving instructors S. B. (male, $37 \mathrm{yr}$ ) and S. M. (female, $29 \mathrm{yr}$ ) took part in the study. They lived on a $18 \mathrm{sq} \mathrm{m}$ set furnished with table, chairs, sofa and exercise machines (bikes and tapis roulant) 


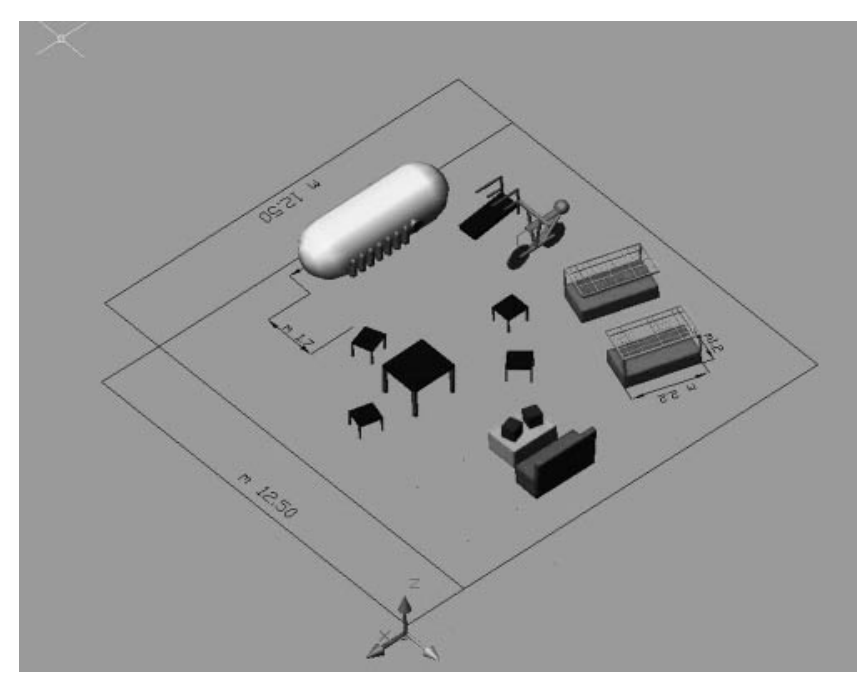

Fig. 1 The $18 \mathrm{sq} \mathrm{m}$ set furnished with table, chairs, sofa and exercise machines (bikes and tapis roulant) anchored to the sea floor (Ponza Island, Italy).

anchored to the sea floor ( Fig. 1). They slept under upturned bedsteads to avoid rising upwards while they were sleeping. They even had a special waterproof TV and books; they played cards, crosswords and sudoku. The divers had almost 11 hours per day of natural light, although the first 3 days of the experiment were cloudy and rainy. The $18 \mathrm{sq} \mathrm{m}$ underwater set had artificial light 24 hours a day. Twenty 100 Watt searchlights were put underwater near the 9 fixed video cameras (there were also 3 mobile video cameras). Two big 500 Watt beacons were pointed on the underwater set from the harbour. The temperature of the sea water varied between 24 and $26^{\circ} \mathrm{C}$, lowering during the night and with north (Tramontana) or north west (Maestrale) wind (prevalent west winds, 8.5 knots).

Divers had availability to choose food prepared by a team of nutritionists. Usually they had low fat food, with a hyperproteic and hyperglicidic diet. They had to choose between fish and meat, boiled vegetables and potatoes. For breakfast S.B. preferred to have coffee and apple juice and often some honey. S.M. also preferred to have yogurt and biscuits.

Every six hours the divers entered an underwater bell where under dry conditions, they tasted the food, defecated and changed their suits and full-face masks. In this dry chamber, medical doctors of the "Progetto Abissi 2005 Dive Medical Group" carried out, every day, regular tests, including drawing for stress hormones levels, breath tests, checks for blood pressure and oxygen levels evaluated by portable saturimeter, heart rate, skin condition and hydration, evaluated by clinical examination.

Blood samples were daily collected ( $8: 00 \mathrm{am})$ by venipuncture in the underwater bell. Samples, put in waterproof bags, were carried out of water. Serum was immediately separated by centrifugation at $1500 \times \mathrm{g}$ for $15 \mathrm{~min}$ and stored at $-20^{\circ} \mathrm{C}$ until analysed. The last day, three samples (8:00 a.m., 6:00 p.m., and 12:00 p.m.) were collected to evaluate the physiological pulsatile cortisol secretion.

Thyroid hormones (FT3, FT4, TSH), cortisol, prolactin, FSH, LH, estradiol, progesterone, testosterone, DHEAS, and IGF-I concentration were measureded by chemiluminescence's immunoassay by Modular Analitics E170 (Roche Diagnostic, Mannheim, Germany). The intra-assay and inter-assay (3 repeated measures for each hormone) coefficient variations were less than $5 \%$.

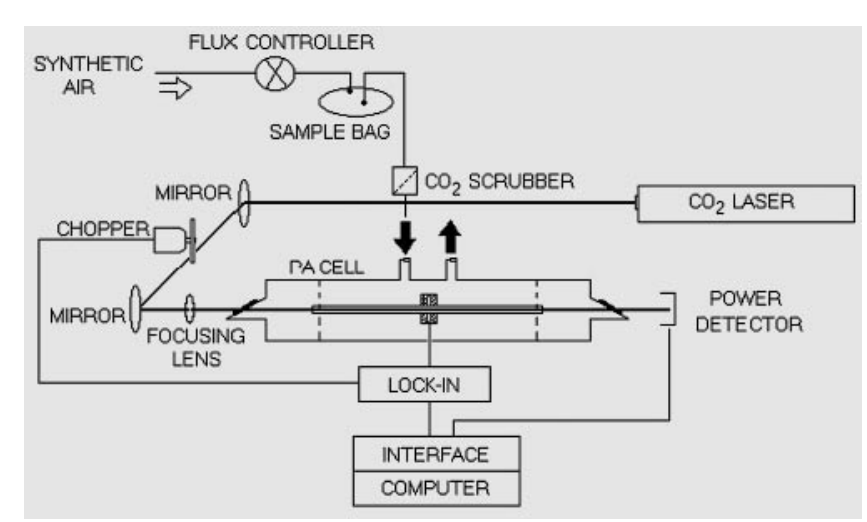

Fig. 2 Scheme of the laser photoacoustic trace gas detector.

Physiological stress assessment by breath test

In different physiological or pathological stress conditions, a higher quantity of free radicals is generated in our body also inducing the lipid peroxidation (LP). The LP process consists in the cellular membrane phospholipides degradation and leads to the release of low weight hydrocarbons such as ethane, pentane, ethylene [9]. Part of the ethylene produced as a consequence of the LP processes and transported to the lungs by the sanguine flux is eliminated with the breath in very low concentrations (ppb). Adopting a sufficiently sensitive method for measuring ethylene, it is possible to determine the extension of the oxidative stress in a very simple and rapid way by means of a breath test (BT) [9]. With this aim, an experiment for detecting any small variation of ethylene concentration in samples of breath exhaled by scuba divers during the prolonged dive was performed. In particular, samples of the breath were collected from both the athletes before, during and after the dive. We followed up the evolution of the ethylene release by using a laser based spectroscopic system realised in ENEA Molecular Spectroscopy Laboratory.

\section{Spectroscopy based breath analysis}

The analysis of the breath samples was made by using the laser photoacoustic spectroscopy (LPAS) in the IR region, a high resolution spectroscopic method able to reveal ethylene traces in air at atmospheric pressure at a sub-ppb level. Infrared absorption spectroscopy is a universal method able to achieve the spectral signature of molecules with high resolution and high sensitivity. The LPAS photoacoustic sensor for ethylene realised in ENEA Frascati, Italy (see the schematic view in the $\odot$ Fig. 2) makes use of a highly stabilised $10 \mathrm{~W} \mathrm{c.w}$. $\mathrm{CO}_{2}$ laser source operating at $10.6 \mu \mathrm{m}\left(949.48003 \times \mathrm{cm}^{-1}\right)$ on the $10 \mathrm{P}_{14}$ line where ethylene shows the strongest absorption. The operation of the apparatus as well as the acquisition of the experimental data is realised by a PC equipped with a GPIB interface and working in a LabView environment. As the photoacoustic (PA) signal is proportional with the laser power, PA spectroscopy (PAS) requires an intense infrared laser beam (order of Watts). This absorption-based technique employs frequency modulation, that in our case is fixed at $550 \mathrm{~Hz}$, to allow the generation of acoustic waves in a resonant PA cell. More details on the system operation were previously reported [9].

The breath samples are collected and stored in special aluminised bags (0.5 liter Quintron) in which the breath has to be exhaled without a previous hyperventilation. The bags are provided by a one-way valve and a mechanism for discarding the bronchial air. For analysing the content of ethylene, the bags are 
transported in the laboratory and the stored breath samples are transferred from the bags into the measuring cell through a $\mathrm{CO}_{2}$ scrubber by means of a synthetic air flux regulated by high precision electronic flux meters. The LPAS apparatus we used already produced results in the field of biology and medicine about the detection of trace ethylene both in vitro and in vivo $[8,17]$.

\section{Psychological assessment}

The subjects were given a questionnaire containing two different self-rating psychometric tests: one for anxiety and the other for depression.

Anxiety was assessed by the State and Trait Anxiety Inventory (STAI test), made up of 2 axes ( $y 1$ for state anxiety and $\mathrm{y} 2$ for trait anxiety) both consisting of 20 multiple choice items in which a rough point score of more than 40 is considered high [18]. This test was selected both on the basis of its simplicity, validity and reliability [7] and because it was already utilised by our group in studies aimed to evaluate anxiety levels and to distinguish "state" anxiety from "trait" anxiety in several diseases $[1-4]$. In particular, the STAI test permits a distinction between existing anxiety and the predisposition to the anxiety reaction as a personality characteristic, as previously described [1-4]. This theory is based on the conceptual distinction between anxiety as a transitory state and anxiety as a relatively stable personality trait. The state anxiety is conceptualised as an emotive state characterised by subjective feelings perceived on a conscious level as apprehension and tension, which varies with time; anxiety as a trait refers to individuals with a relatively stable continuous disposition towards anxiety.

In regard to the depression assessment, we used a currently validated test, the Zung self-rating depression scale $[10,19]$, made up of 20 multiple choice items in which a rough point score of more than 49 is considered high. The point score of this scale is based on the frequency of depressive symptoms; minor symptoms which occur frequently, therefore, have a high score. This test constitutes an effective instrument in screening for depression in a clinical setting $[10,11]$, and its positive predictive value of a diagnosis of current depression is between $88.7 \%$ and $92.3 \%$ [13].

The scales were administered at the start of the study, before the diving (T0), every two days of diving (T1 - T4) and at the end of the study at the emergence (T5).

\section{Results}

$\nabla$

During the 10 day scuba dive, a decrease of 1.8 kilos of body weight was found in S.B. (before the experiment he weighted $76 \mathrm{~kg}$ ). His blood pressure was 130 (systolic) and 80 (diastolic) $\mathrm{mmHg}$ and his hearth rate was 67 pulse beat/minute (PBM) before the dive. These values remained steady during the diving period, although a decrease of blood pressure to a value of 95 (systolic) and 60 (diastolic) $\mathrm{mmHg}$ was found on the evening of the seventh day. The subject had to be put on a drip in the bell since he showed clinical symptoms of collapse. He recovered in a short time being able to continue the experiment. After the dive, values of 130 (systolic), 70 (diastolic) and 70 PBM were detected.

A decrease of 3.8 kilos body weight was found in S. M. (before the experiment she weighted $62 \mathrm{~kg}$ ). Her blood pressure was 105 (systolic) and 70 (diastolic) $\mathrm{mmHg}$ and her hearth rate was 72 PBM before the dive. These values remained steady during the diving period, although a slight increase of blood pressure to a value of 125 (systolic) and 80 (diastolic) $\mathrm{mmHg}$ was found at the morning of the third day, without clinical symptoms. After the dive, values of 115 (systolic), 80 (diastolic) and 78 PBM were detected.

In both divers, the oxygen level was always between 96 to $99 \%$. In both divers, the skin appeared in good conditions. Body temperature, taken in the bell, the third day underwater was 36.0 (S.B.) and $36.2^{\circ} \mathrm{C}$ (S.M.); their usual body temperature is $0.5^{\circ}$

Table 1 Hormone values of the two subjects examined at the start of the study, before the dive (T0), every two days of diving (T1 - T4) and at the end of the study at the emersion (T5)

\begin{tabular}{|c|c|c|c|c|c|c|}
\hline Hormone (normal range) & TO & T1 & T2 & T3 & T4 & T5 \\
\hline \multicolumn{7}{|l|}{ S. M. female* } \\
\hline FT3 $(2.3-4.2 \mathrm{pg} / \mathrm{ml})$ & 2.97 & 3.45 & 2.86 & 3.18 & 3.12 & 3.12 \\
\hline FT4 (8.5- $15.5 \mathrm{ng} / \mathrm{l})$ & 11.0 & 12.47 & 11.54 & 11.45 & 12.26 & 12.20 \\
\hline $\mathrm{TSH}(0.35-2.80 \mu \mathrm{IU} / \mathrm{ml})$ & 1.18 & 0.896 & 0.419 & 0.970 & 1.39 & 1.18 \\
\hline PRL (3.5 - $26.5 \mathrm{ng} / \mathrm{ml})$ & 9.79 & 10.11 & 6.11 & 14.47 & 25.20 & 16.39 \\
\hline${ }^{*} \mathrm{FSH}(2.5-11 \mathrm{mUI} / \mathrm{ml})$ & 3.40 & 2.95 & 2.30 & 2.01 & 1.89 & 2.33 \\
\hline${ }^{*} \mathrm{LH}(2.5-10.0 \mathrm{mUI} / \mathrm{ml})$ & 2.41 & 1.17 & 0.350 & 0.605 & 0.853 & 2.23 \\
\hline * Estradiol (30.0-100 pg/ml) & 16.81 & 13.40 & 16.11 & 16.32 & 18.39 & 17.38 \\
\hline * Progesterone $(0.3-0.8 \mathrm{ng} / \mathrm{ml})$ & 0.234 & 0.304 & 0.196 & 0.247 & 0.317 & 0.245 \\
\hline Testosterone $(0.20-0.60 \mathrm{ng} / \mathrm{ml})$ & 0.176 & 0.242 & 0.165 & 0.188 & 0.252 & 0.224 \\
\hline DHEA-S (1000.0 - $3500.0 \mathrm{ng} / \mathrm{ml})$ & 1046 & 1469 & 1072 & 1160 & 1243 & 1147 \\
\hline IGF-1 (80 - $300 \mathrm{ng} / \mathrm{ml})$ & 172.0 & 153.9 & 209.7 & 177.9 & 152.5 & 164.2 \\
\hline \multicolumn{7}{|l|}{ S. B. male } \\
\hline FT3 $(2.3-4.2 \mathrm{pg} / \mathrm{ml})$ & 4.19 & 4.68 & 4.03 & 3.95 & 4.64 & 4.52 \\
\hline FT4 (8.5 - $15.5 \mathrm{ng} / \mathrm{l})$ & 12.66 & 13.77 & 12.86 & 12.63 & 14.78 & 14.76 \\
\hline $\mathrm{TSH}(0.35-2.80 \mu \mathrm{IU} / \mathrm{ml})$ & 0.708 & 0.843 & 0.574 & 0.570 & 1.81 & 1.36 \\
\hline FSH (2.5 - $11 \mathrm{mUI} / \mathrm{ml})$ & 5.96 & 5.03 & 3.93 & 4.27 & 4.47 & 2.97 \\
\hline Estradiol (10.0 - $35.0 \mathrm{pg} / \mathrm{ml})$ & 25.71 & 27.24 & 27.30 & 23.65 & 32.64 & 24.15 \\
\hline Progesterone $(0.2-0.4 \mathrm{ng} / \mathrm{ml})$ & 0.725 & 0.767 & 0.700 & 0.820 & 0.676 & 0.549 \\
\hline Testosterone (3.50-10.0 ng/ml) & 7.47 & 8.42 & 7.18 & 6.88 & 6.89 & 7.55 \\
\hline DHEA-S (1000.0 - $3500.0 \mathrm{ng} / \mathrm{ml})$ & 3394 & 3071 & 2527 & 3176 & 2838 & 2174 \\
\hline IGF-1 (80 - $300 \mathrm{ng} / \mathrm{ml})$ & 179.6 & 173.3 & 179.4 & 193.2 & 173.7 & 176.4 \\
\hline
\end{tabular}

\footnotetext{
* In female subject sexual hormones were not linked to physiological cycle phases due to concomitant estroprogestinic therapy
} 


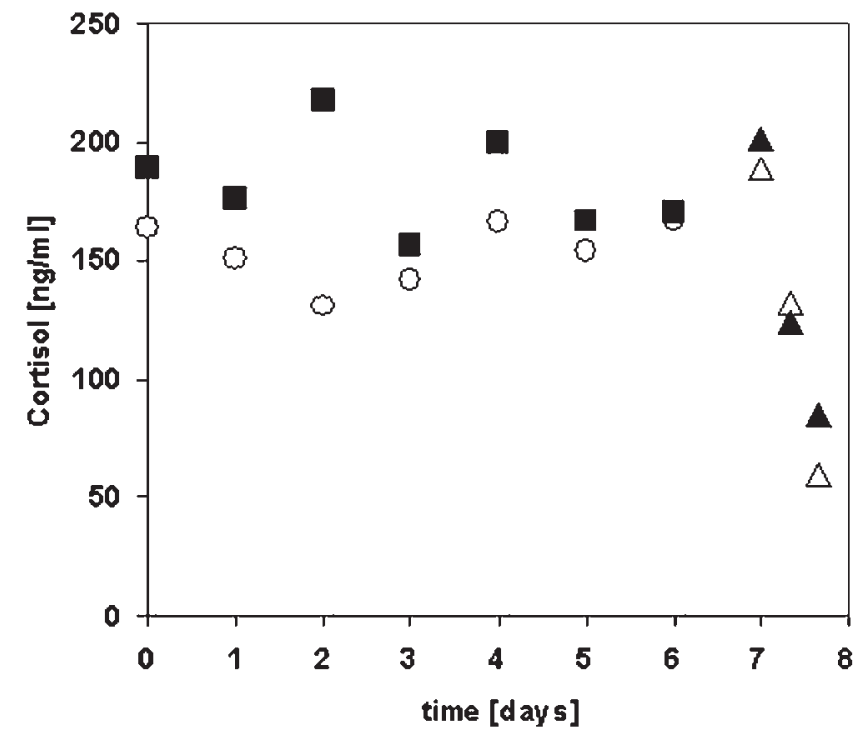

Fig. 3 Square points show male (white) and female (black) subject cortisol concentration at 8:00 am, as function of time from first (day "zero") to sixth day. Triangle points show male (white) and female (black) subject cortisol concentration at seventh day, as function of cortisol circadian rhythm (8:00 a.m., 4:00 p.m., and 12:00 p.m.).

higher. Despite the constant medical attention, the divers are reported to have found it difficult to avoid getting cold, fatigued and dehydrated.

In the studied subjects, cortisol ( $\odot$ Fig. 3 ) and prolactin showed physiological pulsatile secretion; thyroid hormones, testosterone, DHEAS, sexual hormones and IGF-I did not show significant inter-days differences in respect to physiological fluctuation in controls subjects ( $\bullet$ Table $\mathbf{1}$ ). In the female subject, sexual hormones were not linked to physiological cycle phases due to concomitant estroprogestinic therapy.

With regards to the breath test analysis, the results about the exhaled ethylene measurements are reported in $\mathbf{0}$ Figs. $\mathbf{4}$ and $\mathbf{5}$. Although this parameter was slightly increased during the dive period, the detected absolute values did not exceed in any case the normal values showed by healthy subjects (around $1 \mathrm{ppb}$.) without physiological stress condition.

In 0 Table $\mathbf{2}$ the scores of the psychometric scales at each time considered are reported. At the start of the study, no subjects showed high levels of state anxiety, trait anxiety and current depression. The score of the psychometric scales remained steady during the diving period and no subjects showed anxiety and/or

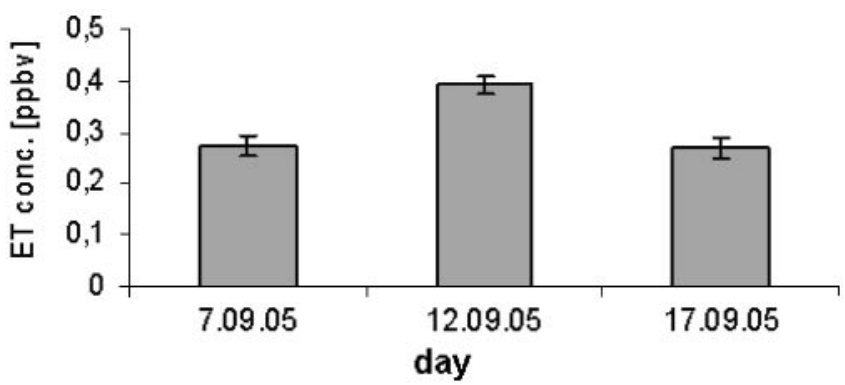

Fig. 4 Ethylene exhaled by the subject S. B. (37 years old, male) in the indicated days: September 7, 2005 (before dive), September 12, 2005 (during dive) and September 17, 2005 (after dive).

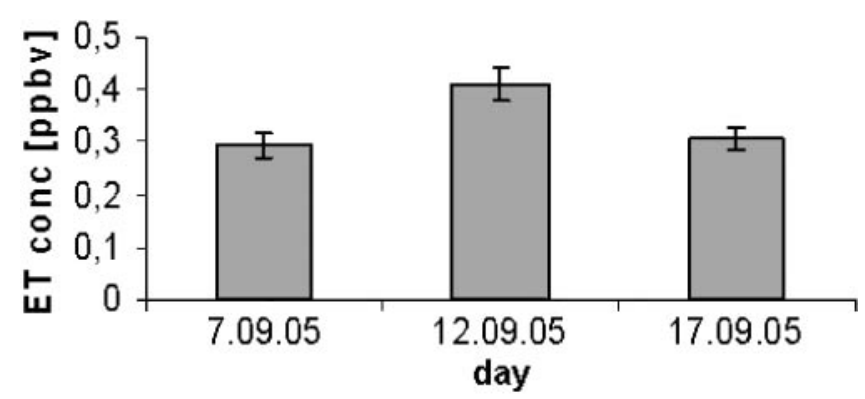

Fig. 5 Ethylene exhaled by subject S.M. (29 years old, female) in the indicated days: September 7, 2005 (before dive), September 12, 2005 (during dive) and September 17, 2005 (after dive).

depression during the time of observation. No subjects showed panic symptoms.

\section{Discussion}

The present study shows that a 240 hour scuba dive does not affect stress parameters, including hormone levels and the cortisol physiological pulsatile secretion. Our data are in line with the recent study by Loder et al. [12] performed on four men which established a new Guinness score by staying submersed in thermoneutral water for 41 hours. In these subjects, hormone levels were evaluated. Contrarily to that expected, no alterations in circulating hormones including circadian cortisol rhythm were found. According to our and Loder et al. data [12], prolonged water submersion does not seem to be a potent stressor, at least in well trained subjects. This observation is also supported by the normal exhaled ethylene values in our divers during the dive period, comparable to those showed in absence of stress condition.

Table 2 State and trait anxiety and depression scores of the two subjects examined at the start of the study, before the dive (T0), every two days of diving ( $\mathrm{T} 1$ T4) and at the end of the study at the emersion (T5)

\begin{tabular}{|c|c|c|c|c|c|c|c|}
\hline Subject & Test & TO & $\mathrm{T} 1$ & $\mathrm{~T} 2$ & T3 & T4 & T5 \\
\hline \multirow[t]{3}{*}{ S.M. } & STAI y 1 & 32 & 33 & 27 & 27 & 27 & 28 \\
\hline & STAI y 2 & 33 & 27 & 28 & 26 & 26 & 26 \\
\hline & ZUNG & 26 & 22 & 23 & 22 & 22 & 22 \\
\hline \multirow[t]{3}{*}{ S.B. } & STAI y 1 & 29 & 27 & 27 & 28 & 28 & 27 \\
\hline & STAI y2 & 31 & 29 & 29 & 29 & 29 & 31 \\
\hline & ZUNG & 24 & 30 & 28 & 28 & 28 & 28 \\
\hline
\end{tabular}

STAI y1: State Anxiety Inventory Scale score; STAI y2: Trait Anxiety Inventory Scale score; ZUNG: Zung Self-Rating Depression Scale score 
Moreover, in our well trained scuba divers, the altered plasma cortisol described after scuba diving in recreational divers [5] did not appear. It could be related to the well training of our subjects and consequently to their high physical fitness. According to this hypothesis, an hyperbaric study showed that hormonal responses exhibit a very individual pattern after hyperbaric exposure and lower levels of physical fitness determine more pronounced hormonal responses [14].

In the subjects examined, no anxiety and/or current depression were found during the experiment. Most of the injuries in scuba divers are due to inappropriate behaviour under stressful diving conditions, mainly involving panic reactions related to high levels of anxiety. It is reported that divers with anxiety and poor coping show a higher risk to develop panic reactions than those possessing more adequate stress-coping-mechanisms [5]. In this connection, it is estimated that 3 to 9 deaths per 100000 divers occur annually in the US, in addition to increasing numbers of cases of decompression illness each year [15]. The main reason for decompression illness and fatalities in divers is rapid ascent, and it appears that the primary stimulus for rapid ascent is panic [15].

The present study shows that, although the long-time diving, the well trained professional divers did not develop state anxiety and/or current depression and no subject discontinued the diving due to occurred psychological disorders or systemic events. It should be underlined that our subjects showed no trait anxiety, suggesting that the evaluation of trait anxiety could be effective in predicting panic risk in scuba diving. Our finding is in line with a recent study performed in students undergoing scuba training [16].

In conclusion, the present report shows that long-term diving permanence is possible, at least in well trained scuba-divers without physical and psychological disorders, even if exposed to extreme conditions.

\section{Members of the "Progetto Abissi 2005 Dive Medical Group" \\ $\nabla$}

Institute of Internal Medicine, Catholic University of Rome, Italy: Lorenzo Leggio, Antonio Mirijello, Cristina D’Angelo, Anna Ferrulli, Luisa Vonghia, Silvia Cardone, Veruscka Leso, Ludovico Abenavoli.

Institute of Endocrine Surgery, Catholic University of Rome, Italy: Marco Raffaelli, Carmela De Crea, Pietro Princi, Antonio Spaventa, Luca Sessa.

Institute of Endocrinology, Catholic University of Rome, Italy: Carlo Rota.

Roman Hyperbaric Centre, Rome, Italy: Corrado Costanzo.

\section{Note}

\section{$\nabla$}

Both authors, L. Revelli and G. Addolorato, contributed equally to the study design and conduction and to the manuscript preparation.

\section{References}

1 Addolorato G, Capristo E, Ghittoni G, Valeri C, Mascianà R, Ancona C, Gasbarrini $G$. Anxiety but not depression decreases in celiac patients after one-year gluten-free diet: a longitudinal study. Scand J Gastroenterol 2001; 36: $502-506$

2 Addolorato G, Capristo E, Stefanini GF, Gasbarrini G. Inflammatory bowel disease: a study of the association between anxiety and depression, physical morbidity, and nutritional status. Scand J Gastroenterol 1997; 32: $1013-1021$

3 Addolorato G, De Lorenzi G, Abenavoli L, Leggio L, Capristo E, Gasbarrini $G$. Psychological support counselling improves gluten-free diet compliance in coeliac patients with affective disorders. Aliment Pharmacol Ther 2004; 20: 777-782

4 Addolorato G, Marsigli L, Capristo E, Caputo F, Dall'Aglio C, Baldanza P, Cammarota G, Graziosetto R, Foschi FG, Stefanini GF, Gasbarrini G. Anxiety and depression: a common feature of health care seeking patients with irritable bowel syndrome and food allergy. Hepatogastroenterology 1998; 45: 1559-1564

5 Anegg U, Dietmaier G, Maier A, Tomaselli F, Gabor S, Kallus KW, SmolleJuttner FM. Stress-induced hormonal and mood responses in scuba divers: a field study. Life Sci 2002; 70: 2721 -2734

6 Doubt TJ. Cardiovascular and thermal responses to SCUBA diving. Med Sci Sport Exerc 1996; 28: 581 - 586

7 Fell M, Newman S, Herns M, Durrance P, Manji H, Conolly S, McAllister R, Weller I, Harrison M. Mood and psychiatric disturbance in HIV and AIDS: changes over time. Brit J Psychiat 1993; 162: 604-610

8 Giubileo G, DeDominicis L, Fantoni R, Francucci M, Congiu Castellano A, Furfaro G, Gaudenzi S, Antonini A, Lombardi CC. Photoacoustic detection of trace ethylene in biogenic gases. Laser Phys 2002; 12: 653-655

9 Giubileo G, Puiu A, Argirò G, Rocchini P, Borra E. Analysis of the breath from patients treated by anti-tumour radio-therapy. Laser Phys 2004; 14: $243-249$

10 Greenough CG, Faser RD. Comparison of eight psychometric instruments in unselected patients with back pain. Spine 1991; 16: 1068 1074

11 Kaplan HI, Sadock BJ (ed). Comprensive Textbook of Psychiatry. New York: Williams \& Wilkins, 1995

12 Loder I, Rossler A, Wurzinger G, Duncko R, Jezova D, Hinghofer-Szalkay H. Adrenomedullin and elements of orthostatic competence after $41 \mathrm{~h}$ of voluntary submersion in water as measured in four healthy males. Eur J Appl Physiol 2006; 96: 644-650

13 Magruder KM, Norquist GS, Feil MB, Kopans B, Jacobs D. Who comes to a voluntary depression screening program? Am J Psychiat 1995; 152: $1615-1622$

14 Mateev G, Djarova T, Ilkov A, Sachanska T, Klissurov L. Hormonal and cardiorespiratory changes following simulated saturation dives to 4 and 11 ATA. Undersea Biomed Res 1990; 17: 1-11

15 Morgan WP. Anxiety and panic in recreational scuba divers. Sports Med 1995; 20: $398-421$

16 Morgan WP, Raglin JS, O'Connor PJ. Trait anxiety predicts panic behavior in beginning scuba students. Int J Sports Med 2004; 25: 314- 322

17 Puiu A, Giubileo G, Bangrazi C. Laser sensors for trace gases in human breath. Intern J Environ Anal Chem 2005; 85: 1001 - 1012

18 Spielberg $C D$, Gorsuch RL, Lushene RE. Manual for the State and Trait Anxiety Inventory. Palo Alto, CA: Consulting Psychologist Press, 1983

19 Zung WW, Richards CB, Short MJ. A self-rating depression scale in outpatient clinic. Further validation of SDS. Arch Gen Psychiat 1965; 13: $508-515$ 